\title{
IMPACTOS PREVIDENCIÁRIOS NA FORMALIZAÇÃO DO MICROEMPREENDEDOR INDIVIDUAL
}

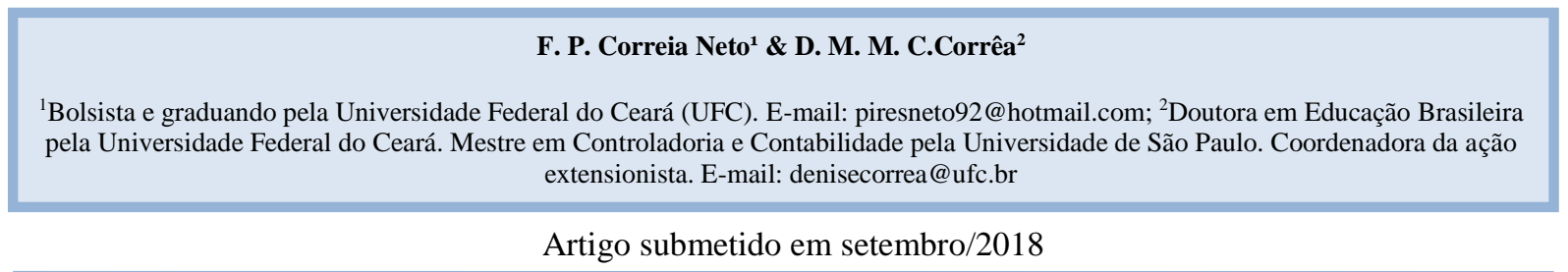

\section{RESUMO}

O empreendedorismo é uma alternativa para auferir renda no Brasil. Considerando os pequenos empreendimentos informais, foi instituída a Lei Complementar 128/2008 com o intuito de estimular a formalização como Microempreendedor Individual (MEI). Essa pesquisa extensionista objetiva verificar os impactos previdenciários da formalização na condição de MEI e analisar as vantagens e desvantagens para o microempresário que formaliza seu empreendimento. Portanto, esse estudo é relevante para os empreendedores que buscam se formalizar. A atual situação da Previdência Social, na qual se discute uma proposta para reforma do sistema, também desperta o interesse em entender o amparo previdenciário do MEI. Utilizou-se pesquisa bibliográfica, através de artigos científicos, livros e obras já publicadas e pesquisa documental, tendo como principal fonte, a legislação aplicável ao Microempreendedor Individual. O instituto do MEI tem caráter de inclusão social e previdenciária, e alguns benefícios previdenciários decorrentes da formalização nesse regime são aposentadoria, auxílio doença e salário maternidade.

PALAVRAS-CHAVE: Microempreendedor Individual. Lei Complementar 128/2008. Impactos previdenciários.

\section{SOCIAL SECURITY IMPACTS IN FORMALIZATION OF THE MICROEMPREENDEDOR INDIVIDUAL}

\begin{abstract}
Entrepreneurship is an alternative to get income in Brazil. Considering small informal business, it was instituted the Federal Law 128/2008 with the intention to stimulate the formalization as Microempreendedor Individual (MEI). This research aims to verify the social security impacts in formalization on condition of MEI and to analyse the advantages and disadvantages to the microentrepreneur who formalizes his business. So, this study is relevant to the entrepreneurs who want the formalization. The current
\end{abstract}

situation of Social Security, in which a proposal to reform the system is discussed, also raises the interest to understand the MEI' social security. It was used bibliographic research, through scientific articles, books and works already published and documental research, using as the main source, the legislation of the Microempreendedor Individual. The institute of MEI has social and social security character, and some social security benefits are retirement, illness aid and maternity leave.

KEYWORDS: Microempreendedor Individual. Federal Law 128/2008. Social Security Impacts

\section{INTRODUÇÃO}

Empreender é uma opção para auferir renda, sobretudo no Brasil, onde o mercado é diversificado, devido ao grande número de habitantes. $\mathrm{O}$ empreendedor é protagonista, sendo 
o responsável por buscar apresentar produtos e serviços inovadores que ensejem o desejo de consumo nos compradores. Nesse sentido, o empreendedorismo tem se desenvolvido no cenário brasileiro, visto que a cada necessidade do consumidor, surge uma oportunidade para o empreendedor criar um produto ou serviço.

Greco et al. (2017, p. 26) revelam que a taxa total de empreendedores no Brasil, com faixa etária entre 18 e 64 anos, era de $21 \%$ em 2002 e passou a 36\% em 2016, considerando os negócios formais e informais pelo país. A partir desse aumento, pode-se constatar que o empreendedorismo, especialmente envolvendo os trabalhadores por conta própria (autônomos), tem se tornado cada vez mais relevante na vida social e econômica de boa parte da população brasileira. Nesse contexto, a Lei Complementar 128/2008 foi criada com o intuito de incentivar a formalização do pequeno empresário como Microempreendedor Individual (MEI). Para tanto, a referida lei estabeleceu tratamento diferenciado ao MEI, concedendo, por exemplo, a formalização gratuita e o acesso à Previdência Social.

A contribuição à Previdência proporciona uma série de benefícios ao segurado como o direito à aposentadoria, ao auxílio doença e ao salário maternidade. A relevância desse estudo se evidencia a partir da necessidade de um melhor esclarecimento aos empresários que buscam se formalizar. Além disso, a atual situação da Previdência Social no Brasil, na qual se discute uma proposta para reforma do sistema, intensifica o interesse em entender como se dá o amparo previdenciário do MEI.

Proveniente do projeto de extensão "Educação Fiscal e Cidadania - implantação do Núcleo de Apoio Contábil e Fiscal (NAF) da Universidade Federal do Ceará”, o presente estudo tem como objetivo geral identificar e analisar as vantagens e desvantagens para o microempresário que formaliza seu empreendimento e, de forma específica, verificar, à luz da LC 128/2008, quais são os impactos de ordem previdenciária da formalização na condição de Microempreendedor Individual (MEI). A metodologia utilizada consiste em uma pesquisa bibliográfica, através de artigos científicos, livros e obras já publicadas e pesquisa documental, tendo como principais fontes, a legislação aplicável ao MEI.

\section{EMPREENDEDORISMO NO BRASIL}

O termo empreendedorismo pode ser associado à dinâmica inerente aos negócios, ou seja, ao ato do empreendedor de investir tempo, capital e esforço em busca de algum retorno. 
É possível afirmar que o risco é pertinente aos negócios, portanto aquele que inicia um empreendimento está sujeito às incertezas do ambiente econômico que o cerca. Quanto ao termo empreendedor, não há consenso na literatura sobre a definição conceitual, embora seja possível afirmar que boa parte das ideias dos autores se complementa. Empreendedor referese a um termo dinâmico e multifacetado, influenciado por revoluções tecnológicas e sociais. (ZEN; FRACASSO, 2008).

Segundo Chiavenato (2007, p. 7), “o empreendedor é a pessoa que consegue fazer as coisas acontecerem, pois é dotado de sensibilidade para os negócios, tino financeiro e capacidade de identificar oportunidades." Nesse contexto, o Brasil é propício para o empreendedor perceber e explorar as oportunidades de fazer negócios, devido à diversidade do mercado consumidor.

Em um cenário competitivo como o brasileiro, inovar para criação de valor pode ser o fator determinante para o sucesso de uma organização. Para Fiorin, Mello e Machado (2010, p. 413), "os empreendedores tentam criar valor e fazer uma contribuição quando reconhecem uma oportunidade, um mercado a ser explorado". As autoras também afirmam que a criação de valor decorre da inovação e da combinação de recursos existentes.

Em síntese, a literatura relaciona o termo empreendedor com aquele que é capaz de identificar oportunidades e de assumir riscos, possuindo como características a inovação e a criatividade, buscando a geração de valor. É importante salientar que esses atributos são explicados de forma ampla, sendo aplicáveis a qualquer empreendedor.

Embora o atributo de identificar oportunidades seja concebido ao empreendedor, no Brasil há outros fatores que influenciam o seu trabalho. Devido à condição socioeconômica, para muitos brasileiros empreender é uma necessidade para enfrentar as dificuldades financeiras. Nesse sentido, Greco et al. (2017, p. 30) afirmam que 19,5\% da população brasileira com faixa etária entre 18 e 64 anos resolvem começar um negócio, por conta de uma eventual oportunidade $(11,2 \%)$ ou por conta de uma necessidade $(8,3 \%)$, considerando os empreendimentos formais e informais pelo país.

\subsection{MICROEMPREENDEDOR INDIVIDUAL}

O Microempreendedor Individual (MEI) é aquele que trabalha por conta própria, tem registro de pequeno empresário e exerce uma das modalidades de serviços, comércio ou 
indústria constantes do anexo XI da Resolução CGSN (Comitê Gestor do Simples Nacional) $n^{\circ} 140$ de 2018 (PORTAL DO EMPREENDEDOR, 2018). A Lei Complementar 128/2008 instituiu a figura jurídica do MEI com o intuito de estimular a formalização dos pequenos negócios. Para tanto, o legislador estabeleceu tratamento diferenciado ao Microempreendedor Individual, ao determinar, entre outros incentivos, a desoneração tributária e a cobertura previdenciária do MEI, conforme será mostrado nesse trabalho.

A escolha pela formalização depende do empreendedor, no entanto, para se enquadrar como MEI, devem ser atendidos alguns requisitos, os quais serão enfatizados os mais relevantes. Segundo o Portal do Empreendedor (2018), o MEI é o pequeno empresário individual que atende às condições relacionadas a seguir:

a) tenha faturamento limitado a $\mathrm{R} \$ 81.000,00$ por ano

b) Que não participe como sócio, administrador ou titular de outra empresa;

c) Contrate no máximo um empregado;

d) Exerça uma das atividades econômicas previstas no Anexo XI, da Resolução CGSN no 140, de 2018, o qual relaciona todas as atividades permitidas ao MEI. (PORTAL DO EMPREENDEDOR, 2018)

O faturamento é uma das formas de se avaliar economicamente uma empresa, inclusive para efeitos de tributação. Portanto, o teto de faturamento anual, no importe de $\mathrm{R} \$ 81.000,00$ para o MEI, revela que o tratamento estabelecido ao pequeno empresário tem estrita observância ao tamanho do empreendimento. Acrescenta-se a isso o disposto na Resolução 140 do Comitê Gestor do Simples Nacional (CGSN, 2018), a qual cita que o Microempreendedor Individual não pode possuir mais de um estabelecimento. Dessa forma, para se enquadrar como microempresário, à luz da legislação, o empreendedor precisa possuir de fato as características de um pequeno negócio.

No que concerne às atividades abrangidas pelo MEI, no anexo XI da Resolução 140 do CGSN, entre as ocupações permitidas aos pequenos empresários, tem-se: as de artesão, cabeleireiro, pintor, proprietário de lanchonete e vendedor ambulante de alimentos. Por outro lado, as profissões regulamentadas, tais como de dentista ou de advogado, por exemplo, não podem se enquadrar como MEI, por não constarem do referido anexo.

Como política de incentivo, o pagamento de tributos do MEI ocorre de forma simplificada em um único documento: o Documento de Arrecadação do Simples (DAS). Conforme a Lei Complementar 123/2006, o valor a ser pago mensalmente pelo MEI corresponde aos seguintes tributos: R \$ 5,00 de ISS, se a atividade for serviço; R \$1,00 de ICMS se for comércio ou indústria; e 5\% do salário mínimo para o INSS. Para facilitar a ilustração, foi elaborada a tabela abaixo: 
Tabela 1 - Valor mensal dos tributos do MEI

\begin{tabular}{lccc}
\multicolumn{1}{c}{ MEI - Atividade } & INSS & ICMS / ISS & Total \\
\hline Comércio - ICMS & $\mathrm{R} \$ 47,70$ & $\mathrm{R} \$ 1,00$ & $\mathrm{R} \$ 48,70$ \\
\hline Serviços - ISS & $\mathrm{R} \$ 47,70$ & $\mathrm{R} \$ 5,00$ & $\mathrm{R} \$ 52,70$ \\
\hline Comércio e Serviços - ICMS e ISS & $\mathrm{R} \$ 47,70$ & $\mathrm{R} \$ 6,00$ & $\mathrm{R} \$ 53,70$ \\
\hline \multicolumn{2}{c}{ Fonte: elaborado pelos autores a partir de dados do Portal do Empreendedor (2018). }
\end{tabular}

Embora o INSS, estabelecido em 5\% do salário mínimo vigente, represente o valor mais significativo entre os tributos, o valor é quase simbólico frente à cobertura previdenciária oferecida ao MEI. Tal assertiva é ratificada pelo artigo $\mathrm{n}^{\circ}$ 18-E da Lei Complementar 147/2014: “o instituto do MEI é uma política pública que tem por objetivo a formalização de pequenos empreendimentos e a inclusão social e previdenciária”.

Quanto ao ICMS e ao ISS, o valor é insignificante, demonstrando o caráter simbólico de arrecadação desses impostos. Isso reforça a política de incentivo à formalização instituída pela Lei Complementar 128/2008 e de inclusão social e previdenciária esclarecida a partir da Lei Complementar 147/2014.

\subsubsection{FORMALIZAÇÃO COMO MICROEMPREENDEDOR INDIVIDUAL}

Desde que foi instituída a LC 128/2008, o número de empreendedores que se formalizam tem crescido constantemente. Segundo o SEBRAE (2013), de julho/2009 a agosto/2013, 3.341.407 empreendimentos foram formalizados no Brasil. Esses dados refletem a decisão de grande parte dos empreendedores informais de se formalizar como MEI, nos cinco primeiros anos da LC 128/2008. Desde então, o aumento da formalização como MEI permaneceu significante. Segundo o Portal do Empreendedor (2018), em 31/07/2018 o total de MEI era de 7.167.054 empreendedores.

Apesar do número de empreendedores formalizados ser expressivo, ainda é alto o percentual de empresas na informalidade, isto é, sem o devido reconhecimento formal pelo governo e órgãos reguladores. Conforme apontam Greco et al (2017, p.73), apenas 17,5\% dos empreendedores entrevistados na pesquisa Global Entrepreneurship Monitor (GEM) em 2016 declararam ter Cadastro Nacional de Pessoas Jurídicas (CNPJ). Logo, 82,5\% dos empreendedores entrevistados atuam na informalidade.

Portanto, embora a legislação tenha buscado incentivar a formalização do MEI, há 
algumas causas que influenciam a permanência na informalidade. Conforme Paes (2010), na visão do trabalhador informal, a escolha por não se formalizar está relacionada a: 1) preços diferenciados que podem atrair o consumidor para o produto informal; 2) fiscalização frágil por parte do governo; 3) não pagamento de impostos, custos trabalhistas e regulatórios e 4) redução de despesas decorrentes de adaptação a regras contábeis.

Por outro lado, alguns impactos positivos da formalização foram mensurados em levantamento realizado pelo SEBRAE (2017), no qual se aplicou questionário com MEIs recém-formalizados, indagando se houve aumento em quatro variáveis decorrentes da formalização, com os seguintes percentuais de respostas afirmativas: 1) Aumento das vendas (78\%); 2) Condições de compra (78\%); 3) Vendas para outras empresas (29\%) e 4) Vendas para a prefeitura ou governo (14\%).

Conforme o SEBRAE (2018), os benefícios da formalização incluem: a tranquilidade em caso de fiscalização, a abertura de conta em banco e o acesso a crédito com juros mais baratos, a cobertura previdenciária para o MEI e sua família, o apoio técnico do SEBRAE, a emissão de nota fiscal para venda a outras empresas e ao governo, além da dispensa da formalidade de escrituração fiscal e contábil.

A desburocratização tem sido um dos aspectos importantes para facilitar a legalização dos pequenos negócios. A formalização é gratuita e deve ser feita pela internet através do Portal do Empreendedor no endereço www.portaldoempreendedor.gov.br (PORTAL DO EMPREENDEDOR, 2018). O processo de formalização é simplificado, conforme se verifica:

Não é necessário encaminhar nenhum documento à Junta Comercial. Após o cadastramento, o CNPJ, a inscrição na Junta Comercial, no INSS e o Alvará Provisório de Funcionamento são obtidos imediatamente, gerando um documento único, que é o Certificado da Condição de Microempreendedor Individual - CCMEI (PORTAL DO EMPREENDEDOR, 2018).

Com isso, pode-se afirmar que a desburocratização é fator de incentivo à formalização, facilitando a abertura de empresas. Segundo afirmam Schwingel e Rizza (2013, p. 47), “o excesso de burocracia é um dos grandes entraves para a formalização e a expansão das empresas, dificultando o ambiente de negócios e comprometendo o desenvolvimento econômico e social do país."

Nesse sentido, instituições como o Serviço Brasileiro de Apoio às Micro e Pequenas Empresas (SEBRAE) e o Núcleo de Apoio Contábil e Fiscal (NAF) são referências quando o assunto é orientar os empreendedores, formalizados ou não. Portanto, essas entidades podem ser inclusive o elo entre a informalidade e a formalização. 


\subsubsection{ENTIDADES DE APOIO AO MICROEMPREENDEDOR INDIVIDUAL}

“As soluções desenvolvidas pelo Sebrae atendem desde o empreendedor que pretende abrir seu primeiro negócio até pequenas empresas que já estão consolidadas e buscam um novo posicionamento no mercado" (SEBRAE, 2018). Esse órgão orienta os empreendedores formalizados ou que estejam buscando a formalização, através do próprio site ou de feiras nacionais amplamente divulgadas. Além disso, oferece cursos e treinamentos, que buscam qualificar a gestão das micro e pequenas empresas. O SEBRAE também realiza amplas pesquisas sobre o MEI, possibilitando que as autoridades, os estudantes, os empresários e a sociedade em geral tenham informações necessárias para discutir possíveis melhorias.

O Núcleo de Apoio Contábil e Fiscal - NAF - é um projeto desenvolvido pela Receita Federal em parceria com as Instituições de Ensino Superior - IES, cujo objetivo é oferecer serviços contábeis e fiscais gratuitos para pessoas físicas e jurídicas de menor poder aquisitivo (RECEITA FEDERAL, 2018). O NAF está presente em todo o Brasil e o Microempreendedor Individual é parte integrante do seu público alvo, especialmente no que se refere à orientação em processos como os de solicitação de enquadramento no SIMEI, emissão do DAS e de parcelamentos. Outros serviços também são oferecidos à população gratuitamente, porém a lista de serviços disponíveis deve ser conferida em cada núcleo.

Após a explanação da sistemática do Microempreendedor Individual, incluindo a informação tratada por este tópico sobre as entidades que apoiam o MEI, esse trabalho apresentará a seguir conceitos importantes à abordagem central do estudo. Portanto, serão expostos os aspectos da Previdência Social do Brasil e a cobertura previdenciária do MEI.

\subsection{PREVIDÊNCIA SOCIAL BRASILEIRA}

A Previdência Social pode ser definida como um seguro público, que garante ao segurado o amparo necessário quando ele perde a capacidade de trabalhar por algum tempo. Para ser amparado, o segurado deve contribuir com valores mensais por determinado período. No Brasil, há três regimes distintos e independentes entre si: o Regime Geral, o Regime Próprio e o Regime Complementar (SECRETARIA DE PREVIDÊNCIA, 2015).

O Regime Geral da Previdência Social (RGPS) é de caráter contributivo e de filiação obrigatória, conforme disposto na Constituição Federal de 1988. Os contribuintes para esse 
regime são os empregadores, empregados assalariados, domésticos, autônomos, contribuintes individuais, trabalhadores rurais. Ressalta-se que o MEI está incluído como contribuinte desse regime. Segundo o art. 201 da $\mathrm{CF} / 88$, tal regime deverá atender a:

$$
\begin{aligned}
& \text { I - cobertura dos eventos de doença, invalidez, morte e idade avançada; } \\
& \text { II - proteção à maternidade, especialmente à gestante; } \\
& \text { III - proteção ao trabalhador em situação de desemprego involuntário; } \\
& \text { IV - salário-família e auxílio-reclusão para os dependentes dos segurados de } \\
& \text { baixa renda; } \\
& \text { V - pensão por morte do segurado, homem ou mulher, ao cônjuge ou } \\
& \text { companheiro e dependentes, observado o disposto no } § 2^{\circ} \text { (BRASIL, 1988). }
\end{aligned}
$$

Nesse contexto, é importante citar que o resultado divulgado pela Secretaria da Previdência (2018) apresentou déficit de R \$ 20,1 bilhões, considerando apenas março de 2018. Isso tem levado a discussões econômicas sobre quais políticas podem ser adotadas para manter o sistema equilibrado, ou seja, com a arrecadação suprindo a concessão de benefícios. "A reforma da Previdência estará entre os principais temas do Congresso Nacional em 2018" (AGÊNCIA SENADO, 2018). É sabido que há necessidade constante de se buscar o equilíbrio entre arrecadação e concessão de benefícios para melhor garantia de sustentação do RGPS. Por isso, no cenário brasileiro atual, é preciso que o governo busque meios eficientes de gerir o sistema previdenciário nacional, em prol das políticas públicas de inserção social e previdenciária como a do Microempreendedor Individual.

O Regime Próprio de Servidores Públicos (RPPS) tem seu fundamento no artigo 40 da Constituição Federal de 1988. Esse regime é compulsório para o servidor público do ente federativo ao qual esteja incluído. Excluem-se deste grupo os empregados das empresas públicas, os agentes políticos, servidores temporários e detentores de cargos de confiança, todos filiados obrigatórios ao Regime Geral (SECRETARIA DE PREVIDÊNCIA, 2015).

O Regime de Previdência Complementar (RPC) se divide em duas categorias: um tem como segurados os servidores públicos federais civis titulares de cargo efetivo da União, suas autarquias e fundações, conforme a Lei 12.618/2012. O outro é o Regime de Previdência Privada Complementar, que pode ser fechada, destinado aos empregados de determinada empresa; ou aberta, com acesso individual a quem tiver interesse.

Observa-se que a maioria dos cidadãos brasileiros, inclusive o MEI, se associa à Previdência Social através do Regime Geral de Previdência Social. Considerando o escopo inicial desse estudo, a seguir será aprofundado o contexto de cobertura previdenciária do MEI.

\subsection{COBERTURA PREVIDENCIÁRIA DO MEI}


O amparo previdenciário do pequeno empresário no Regime Geral da Previdência Social decorre da formalização como Microempreendedor Individual (MEI). Além da formalização, o empreendedor precisa contribuir mensalmente com o valor equivalente a $5 \%$ do salário mínimo, segundo redação dada pela Lei Federal 12.470/2011. Ressalta-se que a cobertura previdenciária se estende aos dependentes do empreendedor.

O valor desembolsado pelo MEI a título de contribuição previdenciária em 2018 equivale a $\mathrm{R} \$ 47,70$, correspondente a $5 \%$ do valor do salário mínimo, por mês e é quitado juntamente com os tributos ICMS e/ou ISS em um único documento: o DAS (Documento de Arrecadação do Simples Nacional). O total do boleto pode chegar no máximo a R \$ 53,70, caso o empresário exerça as atividades de comércio e serviço.

A cobertura previdenciária do MEI envolve uma série de direitos, no entanto, para alguns, é necessário observar a carência, que é o tempo mínimo que o empreendedor deve contribuir para estar amparado pelo benefício. Conforme cita o Portal do Empreendedor (2018), os benefícios para o Microempreendedor Individual são:
a) Aposentadoria por idade: mulher aos 60 anos e homem aos 65, observado a carência, que é tempo mínimo de contribuição de 180 meses, a contar do primeiro pagamento em dia; especificamente para esse benefício, mesmo que o segurado pare de contribuir por bastante tempo, as contribuições para aposentadoria nunca se perdem, sempre serão consideradas para a aposentadoria.
b) Auxílio doença e Aposentadoria por invalidez: são necessários 12 meses de contribuição, a contar do primeiro pagamento em dia. É importante saber que, em relação ao benefício auxílio-doença e aposentadoria por invalidez, nos casos de acidente de qualquer natureza ou se houver acometimento de alguma das doenças especificadas em lei, independe de carência a concessão desses dois benefícios.
c) Salário-maternidade: são necessários 10 meses de contribuição, a contar do primeiro pagamento em dia. (PORTAL DO EMPREENDEDOR, 2018)

Observa-se que, em geral, o MEI tem direito a aposentaria por idade, mas não por tempo de contribuição. Porém, conforme o SEBRAE (2018), para ter direito a aposentadoria por tempo de contribuição, o MEI deverá completar a contribuição mensal (atualmente de 5\%) com mais $15 \%$ sobre o salário mínimo, totalizando $20 \%$. No entanto, o cálculo da diferença e a guia para pagamento só se obtém em uma das Agências do INSS.

De outro modo, a política que concede a aposentadoria por idade ao Microempreendedor Individual é significante. "Em termos nominais, um ano de pagamento de benefícios para o MEI (13 salários mínimos) exigiria quase 22 anos de contribuição (21,7 anos de contribuição de 60\% do salário mínimo)", afirma Constanzi (2018, p.7). Em outras palavras, o recebimento de 13 salários mínimos como benefício previdenciário pelo MEI 
corresponde a $\mathrm{R} \$ 12.402,00$. O MEI precisaria pagar 260 parcelas (260 meses ou 21,7 anos) para contribuir R \$12.402,00 para a Previdência Social.

Considerando o cenário anterior à LC 128/2008 e à lei 12.470/2011, é importante mencionar que o Decreto 6.042/07 reduziu a alíquota do contribuinte individual classificado como de baixa renda de 20\% para 11\% sobre o salário mínimo. Em 2011, a Lei Federal 12.470/2011 estabeleceu outra redução de alíquota para incentivar a cobertura previdenciária do empreendedor autônomo, reduzindo então de $11 \%$ para $5 \%$ sobre o salário mínimo, inclusive abrangendo um público maior que o tratado pelo Decreto supracitado. Isso demostra claramente o caráter de inclusão social e previdenciária aos empreendedores individuais, introduzido pelas leis que tratam do Microempreendedor Individual, visto que o valor requerido atualmente para esse contribuinte se filiar à Previdência é de $\mathrm{R} \$ 47,70$, por mês.

Os benefícios de auxílio doença e de aposentadoria por invalidez proporcionam aos empreendedores a segurança para manter o sustento, caso ocorra algum imprevisto. Desse modo, a política de concessão desses benefícios representa uma visão humana, solidária e social. Inclusive, em situações específicas, como nos casos de acidente de qualquer natureza, a concessão desses dois benefícios dispensa a carência, o que reforça o caráter social da política de inclusão do MEI na Previdência.

Quanto ao salário maternidade, é importante ressaltar que se deve observar a carência e efetuar os pagamentos em dia para ter garantido o acesso ao benefício. Em resumo, o amparo previdenciário ao pequeno empreendedor se mostra amplo e atende a qualquer empresário que atenda aos requisitos legais e se formalize como MEI.

Referente ao amparo previdenciário dos dependentes, há dois benefícios previstos: a pensão por morte e o auxílio reclusão. Ambos possuem carência e características que variam conforme a idade e o tipo do beneficiário. Pela natureza relativa, será exposto como exemplo o benefício vitalício, que ampara o cônjuge do empreendedor, caso este venha a falecer e já tenha efetuado 18 contribuições mensais e a falência ocorra pelo menos 2 anos após o início do casamento ou da união estável.

De acordo com o SEBRAE (2017, p.59), 26\% dos empreendedores tiveram como principal motivo para se formalizar o acesso aos benefícios do INSS. Tal assertiva permite afirmar que a cobertura previdenciária oferecida pela formalização tem influenciado significativamente na escolha dos empreendedores em se formalizar. 


\section{MATERIAIS E MÉTODOS}

Como metodologia utilizou-se a pesquisa bibliográfica e a documental. "A pesquisa bibliográfica é desenvolvida com base em material já elaborado, constituído principalmente de livros e artigos científicos" (GIL, 2008, p.50). Esta se aplicou para a parte conceitual abordada nesse estudo, especialmente no tópico sobre empreendedorismo no Brasil, em que a seleção dos autores foi baseada no caráter didático, na semelhança com o tema em questão e na completude das obras. Seguindo com o intuito de expor como se conduziu o presente trabalho, se faz necessário diferenciar a pesquisa bibliográfica da documental:
A pesquisa documental assemelha-se muito à pesquisa bibliográfica. A única diferença entre ambas está na natureza das fontes. Enquanto a pesquisa bibliográfica se utiliza fundamentalmente das contribuições dos diversos autores sobre determinado assunto, a pesquisa documental vale-se de materiais que não receberam ainda um tratamento analítico, ou que ainda podem ser reelaborados de acordo com os objetivos da pesquisa. (GIL, A.C., 2008, p. 51).

Tendo em vista o escopo desse estudo, utilizou-se em grande parte da pesquisa documental. Portanto, a legislação aplicável ao Microempreendedor Individual e as informações apresentadas por órgãos oficiais representam a principal fonte na qual esse estudo está fundamentado, principalmente no tocante aos aspectos da formalização e dos benefícios previdenciários. Além disso, os dados de pesquisas efetuadas por entidades oficiais como o IPEA (Instituto de Pesquisa Econômica Aplicada), o Portal do Empreendedor e o SEBRAE foram essenciais ao desenvolvimento do trabalho, especialmente para explicar o cenário socioeconômico brasileiro e a dimensão alcançada pela sistemática do MEI.

O estudo se caracteriza como descritivo em relação aos objetivos, e qualitativo quanto à abordagem do problema. Conforme Gil (2008, p. 28), "as pesquisas deste tipo (descritivas) têm como objetivo primordial a descrição das características de determinada população ou fenômeno ou o estabelecimento de relações entre variáveis." Em relação à abordagem do problema, Richardson $(1999$, p. 82) afirma que "os estudos que empregam uma metodologia qualitativa podem descrever a complexidade de determinado problema, analisar a interação de certas variáveis, compreender e classificar processos dinâmicos vividos por grupos sociais."

\section{RESULTADOS E DISCUSSÕES}

Constatou-se que com a criação da Lei Complementar 128/2008, a formalização dos 
negócios no Brasil tem aumentado consideravelmente. No ano de 2018, que a referida lei completa 10 anos de vigência, 7.167.054 empreendedores já se registraram como Microempreendedor Individual, tomando por base a data de 31/07/2018.

Por outro lado, apesar de a legislação incentivar a formalização, pesquisas apontam que anda é alto o percentual de trabalhadores autônomos que permanecem na informalidade. $\mathrm{Na}$ percepção das vantagens e desvantagens da formalização, embora os empreendedores informais tenham razões próprias para continuar na informalidade, há consenso de que os benefícios associados à formalização como Microempreendedor Individual são mais consistentes e perceptíveis que as desvantagens.

Os impactos sociais da política de inserção do Microempreendedor Individual na Previdência Social são significativos, tendo em vista a quantidade de pessoas amparadas (que inclui o MEI, seus dependentes e o trabalhador contratado pelo MEI com a carteira assinada) após a criação da LC 128/2008. Nesse mesmo sentido, considerando o cenário da Previdência Social no Brasil, pesquisas apontam que o valor arrecadado pelo governo é inferior ao que deve ser concedido como aposentadoria ao MEI, o que pode significar desequilíbrio financeiro nas contas da Previdência quando for conceder essas aposentadorias.

\section{CONCLUSÃO}

É evidente a influência da Lei Complementar 128/2008 na formalização dos trabalhadores por conta própria como Microempreendedor Individual (MEI). Tendo em vista as vantagens como a desoneração de tributos e os benefícios previdenciários desse regime, denota-se o caráter social da política que incentiva a formalização como MEI.

Os impactos previdenciários decorrentes da formalização como Microempreendedor Individual são positivos para o pequeno empresário, haja vista o acesso a uma série de benefícios da Previdência Social, precisando contribuir mensalmente com o valor de apenas 5\% do salário mínimo. Por outro lado, considerando a situação da Previdência Social, o valor arrecadado pelo governo é proporcionalmente inferior ao que deve ser concedido aos MEIs quando estes buscarem a aposentadoria por idade, o que pode representar um desequilíbrio nas contas da Previdência. No entanto, ressaltamos que é preciso que as autoridades busquem meios eficientes de gerir o sistema previdenciário a fim de garantir importantes políticas públicas de inserção social como a do Microempreendedor Individual. 
Entender a sistemática do Microempreendedor Individual é imprescindível para compreendermos o cenário socioeconômico do nosso país, visto que o mercado informal de feirantes, autônomos e ambulantes, por exemplo, representa boa parte da população. Portanto, reforçamos a importância de pesquisas tratando sobre as temáticas de empreendedorismo, informalidade, formalização e cobertura previdenciária, sobretudo dos pequenos negócios a fim de se propor a discussão e as possíveis melhorias.

\section{REFERÊNCIAS}

BRASIL, Agência Senado. Reforma da Previdência deve mobilizar o Congresso neste início de ano. Disponível em $<$ https://www12.senado.leg.br/noticias/materias/2018/02/01/reforma-da-previdencia-vaimobilizar-o-congresso-neste-inicio-de-ano>. Acesso em 13 ago. 2018.

BRASIL, Constituição (1988) Constituição da República Federativa do Brasil. Brasília, DF: Senado Federal, 1988.

BRASIL, Decreto $\mathbf{n}^{\mathbf{0}}$ 6.042 de 12 de fevereiro de 2007. Altera o Regulamento da Previdência Social. Disponível em < http://www.planalto.gov.br/ccivil_03/_ato20072010/2007/decreto/d6042.htm>. Acesso em 10 ago. 2018.

BRASIL, Lei Complementar $\mathbf{n}^{\circ} .123$ de 14 de dezembro de 2006. Institui o Estatuto Nacional da Microempresa e da Empresa de Pequeno Porte. Disponível em <http://www.planalto.gov.br/ccivil_03/leis/LCP/Lcp123.htm>. Acesso em 25 jul. 2018.

BRASIL, Lei Complementar $\mathbf{n}^{\mathbf{0}} \mathbf{1 2 8}$ de 19 de dezembro de 2008. Altera a Lei Complementar $\mathrm{n}^{\circ} 123$, de 14 de dezembro de 2006. Disponível em <http://www.planalto.gov.br/ccivil_03/leis/LCP/Lcp128.htm>. Acesso em 20 jul. 2018.

BRASIL, Lei Complementar $\mathbf{n}^{0} .147$ de 07 de agosto de 2014. Disponível em <http://www.planalto.gov.br/ccivil_03/LEIS/LCP/Lcp147.htm>. Acesso em 28 jul. 2018.

BRASIL, Lei $\mathbf{n}^{\circ}$. 12.470 de 31 de agosto de 2011. Disponível em <http://www.planalto.gov.br/ccivil_03/_Ato2011-2014/2011/Lei/L12470.htm>. Acesso em 13 ago. 2018.

BRASIL, Receita Federal. Núcleo de Apoio Contábil Fiscal. Disponível em <http://idg.receita.fazenda.gov.br/acesso-rapido/direitos-e-deveres/educacao-fiscal/naf>. Acesso em 12 ago. 2018.

BRASIL, Resolução CGSN no 140, de 22 de maio de 2018. Disponível em $<$ http://normas.receita.fazenda.gov.br/sijut2consulta/link.action?visao $=$ anotado\&idAto $=92278$ $>$ Acesso em 15 jul. 2018.

BRASIL, Secretaria da Previdência. Previdência Social. Disponível em $<$ http://www.previdencia.gov.br/perguntas-frequentes/previdencia-social/>. Acesso em $30 \mathrm{jul}$. 2018. 
BRASIL, Secretaria da Previdência. RGPS: Déficit da Previdência em março é de R\$ 20,1 bilhões. Disponível em < http://www.previdencia.gov.br/2018/04/rgps-deficit-da-previdenciaem-marco-e-de-r-201-bilhoes/>. Acesso em 30 jul. 2018.

CHIAVENATO, I. Empreendedorismo: dando asas ao espírito empreendedor. 2. ed. rev. e atualizada. São Paulo: Saraiva, 2007.

CONSTANZI, R. N. (Coord.) Os Desequilíbrios Financeiros do Microempreendedor

Individual (MEI). Brasília: IPEA, 2018. (Carta de Conjuntura $\mathrm{n}^{\circ} .38-1^{\circ}$ trimestre de 2018).

FIORIN, M. M. B.; MELLO, C. M.; MACHADO, H.V. Empreendedorismo e Inovação: análise dos índices de inovação dos empreendimentos brasileiros com base nos relatórios do GEM de 2006, 2007 e 2008. Rev. Adm. UFSM, Santa Maria, v.3, n.3, p.411-423, 2010.

GIL, A. C. Métodos e técnicas de pesquisa social. 6. ed. São Paulo: Atlas, 2008.

GRECO, S. M. S. S. (Coord.). Global Entrepreneurship Monitor - Empreendedorismo no Brasil: 2016. Curitiba: IBQP, 2017.

PAES, N. L. Mudanças no sistema tributário e no mercado de crédito e seus efeitos sobre a informalidade no Brasil. Nova Economia, v. 20, n. 2, 2010, p. 315-340.

PORTAL DO EMPREENDEDOR, O que é ser um MEI? Disponível em

<http://www.portaldoempreendedor.gov.br/temas/quero-ser/formalize-se/O-que-e-ser-ummei> Acesso em 18 jun. 2018.

PORTAL DO EMPREENDEDOR, Dúvidas relacionadas ao Microempreendedor

Individual. Disponível em <http://www.portaldoempreendedor.gov.br/duvidas-frequentes>. Acesso em 15 jun. 2018.

RICHARDSON, R. J. Pesquisa social: métodos e técnicas. 3. ed. São Paulo: Atlas, 1999.

SEBRAE. Direitos e deveres do MEI. Disponível em

<http://www.sebrae.com.br/sites/PortalSebrae/sebraeaz/direitos-e-deveres-do-

mei,b6d5d4361e3c8410VgnVCM2000003c74010aRCRD>. Acesso em 23 ago. 2018.

SEBRAE. Perfil do Microempreendedor Individual 2013. Brasília: i-Comunicação, 2013.

SEBRAE. Perfil do Microempreendedor Individual 2017. Brasília: [s.n.], 2017.

SEBRAE. Quem somos. Disponível em

<http://www.sebrae.com.br/sites/PortalSebrae/canais_adicionais/conheca_quemsomos>.

Acesso em 12 ago. 2018.

SCHWINGEL, I.; RIZZA, G. Políticas Públicas para formalização das empresas: lei geral das micro e pequenas empresas e iniciativas para a desburocratização. Governo Federal, Ministério do Trabalho e Emprego, v. 54, p. 47, 2013.

ZEN, A. C.; FRACASSO, E. M. Quem é o empreendedor? As implicações de três revoluções tecnológicas na construção do termo empreendedor. RAM - Revista de Administração Mackenzie, v. 9 n. 8, Edição especial, 2008. 